\title{
DoE based failure mode effect analysis (FMEA) to development of stability indicating HPTLC method for estimation of apremilast
}

\author{
Pintu Prajapati $^{1} \cdot$ Hitika B. Patel $^{1} \cdot$ Shailesh Shah ${ }^{1}$
}

Received: 18 March 2020 / Accepted: 20 April 2020 / Published online: 13 July 2020

(c) Springer Nature Switzerland AG 2020

\begin{abstract}
DoE based failure mode effect analysis has been performed for implementation of analytical quality by design approach in development of stability indicating assay method for estimation of apremilast. Failure modes were identified, categorized and listed in Ishikawa diagram on bases of preliminary experimentation and sound science of chromatography. Identified failure modes were analysed by allotting risk priority number according to their effect, severity and detectibility during preliminary experimentation. Seven failure modes were found high RPN scores were screened for their main effect on critical quality attributes by Taguchi OA design. Critical method variables volume of methanol, saturation time and migration distance were further taken to Box-Behnken design to establish relationship between critical method variables and resolution. After response surface methodology method operable design space was obtained by optimization of model and control strategy was developed. The chromatographic separation was performed using aluminium backed pre-coated with silica gel 60F254 as stationary phase and toluene:methanol:ethyl acetate $(7: 2: 1 \% \mathrm{v} / \mathrm{v} / \mathrm{v})$ as mobile phase at wavelength of $241 \mathrm{~nm}$. The method was validated as per ICH Q2(R1) guideline. Developed method was applied for assay of Apremilast in its tablet dosage form and results were found in good agreement with labeled claim.
\end{abstract}

Keywords Apremilast · Analytical quality by design · Failure mode effect analysis · Taguchi OA design · Box-Behnken design

\section{Introduction}

Apremilast (Fig. 1) is one of the recent drugs that has been introduced for treatment of psoriaticarthritis. Psoriatic arthritis (PsA) is an autoimmune inflammatory disease that affects both peripheral and axial joints, and the skin. Apremilast is responsible for inhibition of PDE-4 (phosphodiesterase-4). Inhibition of PDE-4 leads to increase in CAMP (cyclic adenosine monophosphate) which cause inhibition of pro-inflammatory cytokines (TNF- $a$, INF- $\gamma$, IL-2) and increase the synthesis of anti- inflammatory mediators (IL-10) and ultimately reduces inflammation [1, 2].

Recently, HPTLC is widely employed for the quantification of drugs because of low maintenance cost, lower analysis time, low mobile phase consumption per sample, and need for minimal sample clean-up. It facilitates automated application of samples and scanning of plates and, moreover, HPTLC as method recently has been proposed to be included in various pharmacopoeias [3].

The traditional OFAT (one-factor-at-a-time) method development generally requires a large number of experiments, while the final outcome is often not the optimal result requiring further development. Analytical quality by design $(A Q b D)$ is a systematic approach of method development that begins with predefined objectives and emphasizes method understanding and its performance, based on sound science and quality risk management. The main objective of $A Q b D$ is to reduce variations in the measurements by controlling various factors that affect method performance thereby resulting in less variation

Pintu Prajapati, pintu.prajapati@utu.ac.in | ${ }^{1}$ Maliba Pharmacy College, Maliba Campus, Uka Tarsadia University, Bardoli, Gujarat, India. 


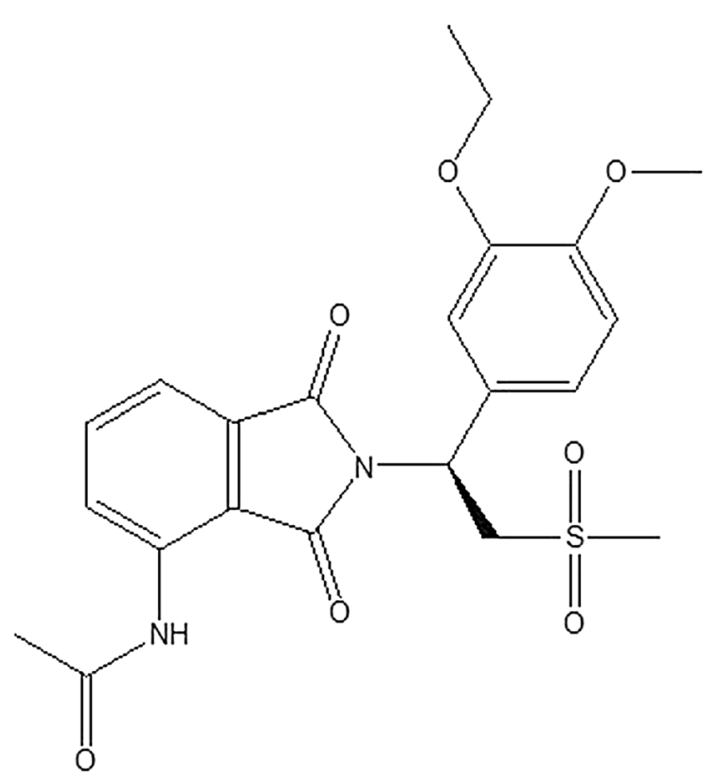

Fig. 1 Chemical structure of Apremilast

in inter laboratory studies and assuring reproducibility. Design of experiment (DoE) is an integral part of $A Q b D$ that includes use of experimental design, mathematical model generation by ANOVA analysis, and graphical representations, showing correlation between factors and response. Therefore, design of experimentation is required to study the effect of previously identified factors affecting the method and defining a robust $A Q b D$ design space where the method can be operated anywhere in that region. Method transfer and reproducibility in inter laboratory studies are the potential benefits of $A Q b D$. A current trend among pharmaceutical industry is to implement $\mathrm{AQbD}$ as a part of risk management, and pharmaceutical quality system and pharmaceutical development [4-10].

An extensive literature survey reveals five stability indicating high performance liquid chromatography and four UV visible spectrophotometry methods for estimation of Apremilast but no stability indicating HPTLC method was found using quality by design approach for estimation of Apremilast [11-13]. Chaudhari et al. have published HPTLC method for estimation of apremilast by application of boxbehnken design but no stress condition applied for development of stability study of apremilast and less number of risk factors have been studied for application of quality by design approach [14]. Bhole et al. have developed A Stability Indicating HPTLC Method for Apremilast but method was developed by conventional approach [15]. Hence no stability indicating HPTLC method has been reported yet. In literature systematic implementation of analytical quality by design based on quality risk management as per regulatory requirement of $\mathrm{ICH} Q 8$ \& Q9 is also lacking. Quality risk management based analytical quality by design approach is helpful for life cycle management of analytical method and easy regulatory approval for new drug applications.

Hence, stability indicating HPTLC method has been developed by analytical quality by design approach based on failure mode effect analysis using Taguchi OA and Box-Behnken design.

\section{Experimental}

\subsection{Instrumentation and reagents}

The HPTLC system (Camag Switzerland) consisting of Linomat V semiautomatic spotting device, TLC Scanner IV (Camag Muttenz, Switzerland), twin-trough developing chamber $(10 \times 10 \mathrm{~cm})$, UV cabinet with dual wavelength UV lamps, winCATS software, syringe $(100 \mu \mathrm{L}$ capacity, Hamilton) were used for chromatographic study. Electronic analytical balance (Shimadzu AUX-220) was used for all the weighing purpose. Apremilast was received as a gift sample from Sun Pharmaceuticals Vadodara. Methanol was purchased from SD Fine Chemicals Limited, Mumbai

\subsection{Preparation of solutions}

\subsubsection{Preparation standard stock solution}

Accurately weighed $10 \mathrm{mg}$ of drug was transferred to $10 \mathrm{~mL}$ volumetric flask and dissolved in few $\mathrm{mL}$ of methanol and diluted up to the mark with methanol $(1000 \mu \mathrm{g} /$ $\mathrm{mL}$ ).

\subsubsection{Preparation of working standard solution}

$1 \mathrm{~mL}$ from the standard stock solution was transferred to $10 \mathrm{~mL}$ volumetric flask and made up to the mark with methanol $(100 \mu \mathrm{g} / \mathrm{mL})$. Aliquot of $5 \mathrm{~mL}$ from above solution was transferred to $10 \mathrm{~mL}$ volumetric flask and made up to the mark with methanol to get working standard solution of $50 \mu \mathrm{g} / \mathrm{mL}$.

\subsubsection{Preparation of forced degraded sample solutions}

Preparation of degraded sample solution in acidic stress condition: $1 \mathrm{~mL}$ of standard stock solution was made up to $10 \mathrm{~mL}$ with $0.1 \mathrm{M} \mathrm{HCl}$ and heated for $2 \mathrm{~h}$ at $60^{\circ} \mathrm{C}$. Resulting solution was transferred to $10 \mathrm{~mL}$ volumetric flask and made up to the mark with methanol. $2 \mathrm{~mL}$ of above solution was neutralized with $0.1 \mathrm{M} \mathrm{NaOH}$ and made up to $10 \mathrm{~mL}$ with methanol. 
Preparation of degraded sample solution in alkaline stress condition: $1 \mathrm{~mL}$ of standard stock solution was made up to $10 \mathrm{~mL}$ with $0.05 \mathrm{M} \mathrm{NaOH}$ and placed for $15 \mathrm{~min}$ at RT. Resulting solution was transferred to $10 \mathrm{~mL}$ volumetric flask and made up to the mark with methanol. $2 \mathrm{~mL}$ of above solution was neutralized with $0.05 \mathrm{M} \mathrm{HCl}$ and made up to $10 \mathrm{~mL}$ with methanol.

Preparation of degraded sample solution in neutral stress condition: $1 \mathrm{~mL}$ of standard stock solution was made up to $10 \mathrm{~mL}$ with distilled water and heated for $2 \mathrm{~h}$ at $50^{\circ} \mathrm{C}$. Resulting solution was transferred to $10 \mathrm{~mL}$ volumetric flask and made up to the mark with methanol. $2 \mathrm{~mL}$ of above solution made up to $10 \mathrm{~mL}$ with methanol.

Preparation of degraded sample solution in oxidative stress condition: $1 \mathrm{~mL}$ of standard stock solution was made up to $10 \mathrm{~mL}$ with $3 \% \mathrm{H}_{2} \mathrm{O}_{2}$ and heated for $4 \mathrm{~h}$ at $80^{\circ} \mathrm{C}$. Resulting solution was transferred to $10 \mathrm{~mL}$ volumetric flask and made up to the mark with methanol. $2 \mathrm{~mL}$ of above solution was made up to $10 \mathrm{~mL}$ with methanol.

Preparation of degraded sample solution in dry heat stress condition: Accurately weighed $10 \mathrm{mg}$ of Apremilast was taken in porcelain dish and kept in the hot air oven at $110 \pm 2^{\circ} \mathrm{C}$ for $4 \mathrm{~h}$. Above sample was transferred to $10 \mathrm{~mL}$ volumetric flask and made up to the mark with methanol. $2 \mathrm{~mL}$ of above solution was made up to $10 \mathrm{~mL}$ with methanol.

Preparation of degraded sample solution in photolytic stress condition: Accurately weighed $10 \mathrm{mg}$ of Apremilast was spreaded on a petridish to make approximately $3 \mathrm{~mm}$ thick layer and was placed in stability chamber at $25 \pm 2{ }^{\circ} \mathrm{C}$ temperature and $10 \%$ relative humidity for 7 days. The light source option 2 has been used for exposure of appropriate wavelength as recommended in ICH Q1B guideline.

\subsection{Failure modes identification and preliminary experimentation}

Various combination of organic solvents have been tried for separation of spots of degradation and apremilast but methanol, ethyl acetate and toluene were found effective solvent system for better separation and compact spot. Other failure modes saturation time, volume of mobile phase, solvent front etc. also checked for their effect on resolution of spots. Instrumental failure modes slit dimension, band width, wavelength for detection etc. also varied for their effect on results. Identified failure modes by preliminary experimentation and sound science of chromatography were categorized and listed in Ishikawa diagram for easy view in further analysis.

\subsection{Failure mode effect analysis (FMEA)}

Each identified failure mode was analysed for its occurrence, severity and detectibility for development of stability indicating HPTLC method. Risk priority number has been allotted to each failure mode by multiplication of its score of occurrence, severity and detectibility. Score for occurrence and severity was allotted to each failure modes by observing its very low (02) to very high effect (10) on resolution and compactness of spots. Score of detectibility was given by ability of detection of failure mode very certain (02) to very uncertain (10). For failure mode effect analysis graph of risk priority number (RPN) verses failure modes were composed and each failure modes was analysed (Table 1).

\subsection{Screening of potential failure modes and CQAs by Taguchi $O A$}

Taguchi OA design was applied for screening of 7 potential method variables such as volume of methanol, volume of mobile phase, migration distance, saturation time, band width, detection wavelength and scanning speed each with two levels and for screening of 4 potential method attributes (resolution between peaks of drug and degradation products) using design expert software (trial version 10.0.7). Eight experimental runs were suggested in design metrics (see Table 2). All runs were performed in laboratory in three replicates. TLC plates were scanned for compact and sharp spot of degradation products and Apremilast with better resolutions. All results were entered against respective experimental run and analysed for effect of potential variables on resolutions.

\subsection{Response surface modeling by Box-Behnken design}

From Pareto chart analysis and ANOVA of screening design, volume of methanol, saturation time and migration distance were found critically affecting method

Table 1 Factors and there levels for Taguchi OA

\begin{tabular}{llll}
\hline Factors & & \multicolumn{2}{l}{ Levels } \\
\cline { 3 - 4 } & & +1 & -1 \\
\hline Factor 1 & Volume of methanol $(\mathrm{mL})$ & 1.5 & 2.5 \\
Factor 2 & Volume of mobile phase $(\mathrm{mL})$ & 8 & 10 \\
Factor 3 & Saturation time $(\mathrm{min})$ & 15 & 45 \\
Factor 4 & Migration distance $(\mathrm{mm})$ & 70 & 80 \\
Factor 5 & Detection wavelength $(\mathrm{nm})$ & 240 & 242 \\
Factor 6 & Scanning speed $(\mathrm{mm} / \mathrm{s})$ & 10 & 20 \\
Factor 7 & Band length (mm) & 4 & 6 \\
\hline
\end{tabular}


Table 2 Design metrics for Taguchi OA

\begin{tabular}{|c|c|c|c|c|c|c|c|c|c|c|c|}
\hline \multirow[t]{3}{*}{ std } & \multicolumn{7}{|c|}{ Factors } & \multirow{2}{*}{\multicolumn{4}{|c|}{$\frac{\text { Response }}{\text { Resolution }}$}} \\
\hline & \multirow[t]{2}{*}{1} & \multirow[t]{2}{*}{2} & \multirow[t]{2}{*}{3} & \multirow[t]{2}{*}{4} & \multirow[t]{2}{*}{5} & \multirow[t]{2}{*}{6} & \multirow[t]{2}{*}{7} & & & & \\
\hline & & & & & & & & 1 & 2 & 3 & 4 \\
\hline 1 & 1.5 & 8 & 4 & 15 & 70 & 240 & 10 & 1.724 & 9.83 & 10.222 & 10.25 \\
\hline 2 & 1.5 & 8 & 4 & 45 & 80 & 242 & 20 & 1.966 & 8.76 & 9.642 & 9.438 \\
\hline 3 & 1.5 & 10 & 6 & 15 & 70 & 242 & 20 & 1.832 & 10.3 & 10.554 & 10.355 \\
\hline 4 & 1.5 & 10 & 6 & 45 & 80 & 240 & 10 & 1.911 & 8.852 & 9.652 & 9.127 \\
\hline 5 & 2.5 & 8 & 6 & 15 & 80 & 240 & 20 & 1.085 & 10.37 & 10.75 & 10.634 \\
\hline 6 & 2.5 & 8 & 6 & 45 & 70 & 242 & 10 & 0.713 & 7.35 & 8.225 & 8.106 \\
\hline 7 & 2.5 & 10 & 4 & 15 & 80 & 242 & 10 & 1.13 & 7.25 & 8.023 & 7.892 \\
\hline 8 & 2.5 & 10 & 4 & 45 & 70 & 240 & 20 & 0.682 & 10.025 & 10.503 & 10.382 \\
\hline
\end{tabular}

Table 3 Factors and their levels for Box-Behnken design

\begin{tabular}{llll}
\hline Factors & \multicolumn{2}{l}{ Levels } & \\
\cline { 2 - 4 } & +1 & 0 & -1 \\
\hline Volume of methanol & 1.5 & 2 & 2.5 \\
Migration distance & 70 & 75 & 80 \\
Saturation time & 15 & 30 & 45 \\
\hline
\end{tabular}

variables and resolution between drug and acid degradation product-1was found critical method attribute. Box-Behnken design was applied for response surface modeling to study relationship between critical method variables and resolution using design expert software (trial version) at three different levels of critical method variables (see Table 3). Seventeen experimental runs were suggested by design metrics for three levels for all the critical factors (see Table 4). All experimental runs were performed in laboratory and resolution for each run was recorded. All responses were entered against respective experimental run and analysed for relationship between critical method attribute and variables. Response surface model was used for optimization of response.

\subsection{Validation of response surface model}

The developed model was validated by comparing actual value of response to predicted value of response. Five solutions were selected from various suggested solutions and were performed experimentally. The actual values of response of individual trials were compared with the predicted values.

\subsection{Optimized chromatographic conditions}

Chromatographic separation was performed on $10 \times 10 \mathrm{~cm}$ aluminum plates pre-coated with $250 \mu \mathrm{m}$ layer of silica gel $60 \mathrm{~F}_{254}$. The TLC plates were pre-washed with methanol
Table 4 Design metrics for Box-Behnken design

\begin{tabular}{lllll}
\hline Std & $\begin{array}{l}\text { Factor 1 } \\
\text { A:Volume of } \\
\text { methanol }\end{array}$ & $\begin{array}{l}\text { Factor } 2 \\
\text { B:Migration } \\
\text { distance }\end{array}$ & $\begin{array}{l}\text { Factor } 3 \\
\text { C:Saturation time }\end{array}$ & $\begin{array}{l}\text { Response } \\
\text { Resolution }\end{array}$ \\
& $\mathrm{mL}$ & Mm & min & \\
\hline 1 & 1.5 & 70 & 30 & 1.806 \\
2 & 2.5 & 70 & 30 & 0.715 \\
3 & 1.5 & 80 & 30 & 1.961 \\
4 & 2.5 & 80 & 30 & 0.836 \\
5 & 1.5 & 75 & 15 & 1.728 \\
6 & 2.5 & 75 & 15 & 0.815 \\
7 & 1.5 & 75 & 45 & 1.624 \\
8 & 2.5 & 75 & 45 & 0.733 \\
9 & 2 & 70 & 15 & 1.498 \\
10 & 2 & 80 & 15 & 1.705 \\
11 & 2 & 70 & 45 & 1.318 \\
12 & 2 & 80 & 45 & 1.558 \\
13 & 2 & 75 & 30 & 1.636 \\
14 & 2 & 75 & 30 & 1.593 \\
15 & 2 & 75 & 30 & 1.568 \\
16 & 2 & 75 & 30 & 1.653 \\
17 & 2 & 75 & 30 & 1.549 \\
\hline & & & & \\
\hline
\end{tabular}

and dried in oven at $50^{\circ} \mathrm{C}$ for $15 \mathrm{~min}$. Samples were spotted on TLC plate at $15 \mathrm{~mm}$ from the bottom edge by Linomat $V$ semi-automatic spotter using following parameters: band width $8 \mathrm{~mm}$; track distance $11.6 \mathrm{~mm}$; application rate, $0.1 \mu \mathrm{l} / \mathrm{s}$. The TLC plate was developed in twin trough chamber using toluene:methanol:ethyl acetate (7:2:1 $\mathrm{v} / \mathrm{v} / \mathrm{v})$ as mobile phase at temperature $25 \pm 2{ }^{\circ} \mathrm{C}$; relative humidity $35 \pm 5 \%$; chamber saturation time $30 \mathrm{~min}$ and migration distance $80 \mathrm{~mm}$. The TLC plate was scanned and analysed by TLC Scanner IV and WinCATS software using following parameters: slit dimension $6 \times 0.45 \mathrm{~mm}$; scanning speed $20 \mathrm{~mm} / \mathrm{sec}$. 


\subsection{Selection of wavelength for detection}

Working standard solution of $20 \mu \mathrm{L}$ of Apremilast was spotted on the TLC plate and plate was developed as per optimized chromatographic conditions. Developed TLC plate was scanned between 200 and $800 \mathrm{~nm}$ for detection of wavelength.

\subsection{Preparation of calibration curve}

From the working standard solution $(50 \mu \mathrm{g} / \mathrm{mL})$ of Apremilast $4,8,12,16$, and $20 \mu \mathrm{L}$ was spotted on TLC plate to get concentration of $200,400,600,800$ and $1000 \mathrm{ng} / \mathrm{band}$ respectively. The plate was developed, dried and analysed according to chromatographic condition. The calibration curve was constructed by plotting peak area versus respective concentration of Apremilast.

\subsection{Analysis of forced degraded sample}

From each forced degraded sample solutions, $30 \mu \mathrm{L}$ was applied to TLC plate. The plate was developed dried and analysed at $241 \mathrm{~nm}$ as described in chromatographic conditions.

\subsection{Method validation (21)}

The method was validated for specificity, linearity, accuracy, inter-day and intra-day precision, repeatability of sample application and repeatability of sample measurement. The detection limit (DL) and quantification limit (QL) were also determined [16].

The specificity of the method was ascertained by analyzing standard drug and marketed formulation. The band for Apremilast in sample was confirmed by comparing the $R_{f}$ value and UV spectra of the band with those obtained from the standard. Linearity of Apremilast was obtained by plotting the mean peak area against their respective concentration over the range of $200-1000 \mathrm{ng} / \mathrm{band}$ $(n=5)$. Repeatability of spotter was determined by analysing seven spots of $600 \mathrm{ng} / \mathrm{band}$ concentration on single plate. Repeatability of scanner was analysed by scanning one spot having concentration of $600 \mathrm{ng} / \mathrm{band}$ for seven times. The results for repeatability were reported in terms of $\%$ RSD. Intraday and interday precision was evaluated by

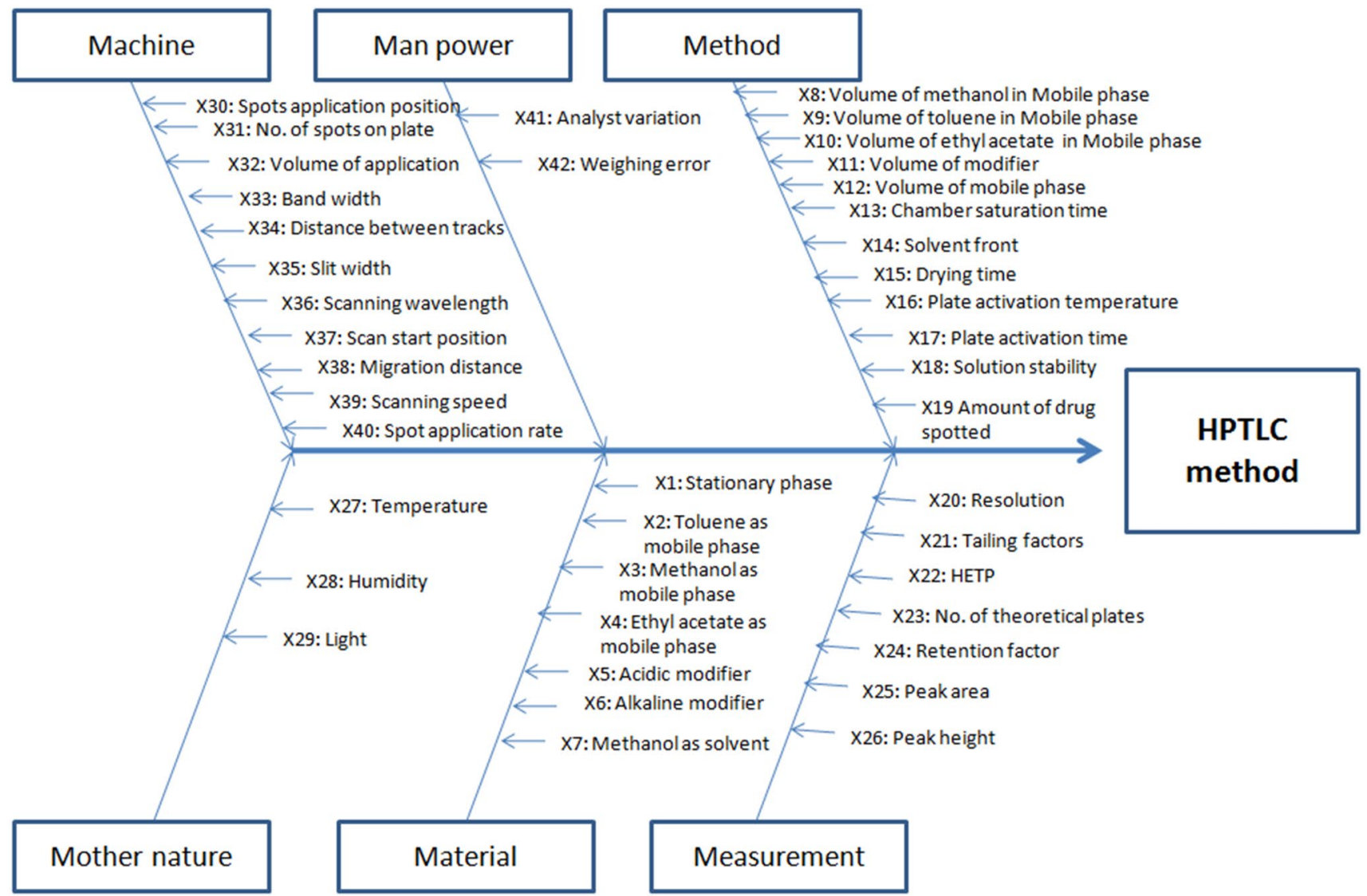

Fig. 2 Ishikawa diagram showing risk factors for development of method 
Table 5 ANNOVA table for Taguchi OA for resolution 1

Table 6 ANNOVA table for Taguchi OA for resolution 2

Table 7 ANNOVA table for Taguchi OA for resolution 3

Table 8 ANNOVA table for Taguchi OA for resolution 4

\begin{tabular}{llllrlrl}
\hline Source & Sum of squares & $d f$ & Mean square & F value & $\begin{array}{l}p \text { value } \\
\text { Prob }>\mathrm{F}\end{array}$ \\
\hline Model & 2.02 & 3 & 0.67 & 304.88 & $<0.0001$ & Significant \\
A-Volume of methanol & 1.83 & 1 & 1.83 & 826.89 & $<0.0001$ & \\
D-Saturation time & 0.031 & 1 & 0.031 & 14.09 & 0.0199 & \\
E-Migration distance & 0.16 & 1 & 0.16 & 73.66 & 0.0010 \\
Residual & $8.837 \times 10^{-3}$ & 4 & $2.209 \times 10^{-3}$ & & & \\
Cor Total & 2.03 & 7 & & & &
\end{tabular}

\begin{tabular}{llllrrr}
\hline Source & Sum of squares & $d f$ & Mean square & F value & \multicolumn{1}{c}{$\begin{array}{l}p \text { value } \\
\text { Prob }>\mathrm{F}\end{array}$} \\
\hline Model & 11.07 & 3 & 3.69 & 480.97 & $<0.0001$ & Significant \\
A-Volume of methanol & 8.64 & 1 & 8.64 & 1125.71 & $<0.0001$ & \\
D-Saturation time & 1.83 & 1 & 1.83 & 238.58 & 0.0001 & \\
E-Migration distance & 0.60 & 1 & 0.60 & 78.63 & 0.0009 \\
Residual & 0.031 & 4 & $7.674 \times 10^{-3}$ & & & \\
Cor Total & 11.10 & 7 & & & &
\end{tabular}

\begin{tabular}{|c|c|c|c|c|c|c|}
\hline Source & Sum of squares & $d f$ & Mean square & F value & $\begin{array}{l}p \text { value } \\
\text { Prob }>F\end{array}$ & \\
\hline Model & 7.66 & 3 & 2.55 & 129.11 & 0.0002 & Significant \\
\hline A-Volume of methanol & 5.26 & 1 & 5.26 & 265.86 & $<0.0001$ & \\
\hline D-Saturation time & 1.64 & 1 & 1.64 & 83.02 & 0.0008 & \\
\hline E-Migration distance & 0.76 & 1 & 0.76 & 38.45 & 0.0034 & \\
\hline Residual & 0.079 & 4 & 0.020 & & & \\
\hline Cor Total & 7.74 & 7 & & & & \\
\hline
\end{tabular}

\begin{tabular}{llllrlrl}
\hline Source & Sum of squares & $d f$ & Mean square & F value & \multicolumn{2}{l}{$\begin{array}{l}p \text { value } \\
\text { Prob }>F\end{array}$} \\
\hline Model & 7.91 & 3 & 2.64 & 88.67 & 0.0004 & Significant \\
A-Volume of methanol & 6.23 & 1 & 6.23 & 209.50 & 0.0001 & \\
D-Saturation time & 1.07 & 1 & 1.07 & 35.96 & 0.0039 & \\
E-Migration distance & 0.61 & 1 & 0.61 & 20.54 & 0.0106 & \\
Residual & 0.12 & 4 & 0.030 & & & & \\
Cor Total & 8.03 & 7 & & & & &
\end{tabular}

analyzing entire calibration range three times on same day and on different days respectively and \%RSD was determined. Accuracy of the method was performed by spiking 80,100 , and $120 \%$ of the standard Apremilast with preanalysed sample of Apremilast in three replicates. LOD and LOQ for the method was determined by using equation as specified in ICH Q2 (R1) guidelines which are as follows.
$L O D=\frac{3.3 \times S D}{S}$

$L O Q=\frac{10 \times S D}{S}$

where SD, Standard deviation of $y$-intercepts of regression lines and S, Mean slope of the calibration curve. 


\subsection{Assay of Marketed formulation}

Accurately weighed tablet powder equivalent to $10 \mathrm{mg}$ of Apremilast was transferred to $10 \mathrm{~mL}$ volumetric flask and filled to about $80 \%$ with methanol then sonicated for $10 \mathrm{~min}$ and diluted up to the mark with methanol. The mixture was filtered through Whatman filter. An aliquot of $1 \mathrm{~mL}$ from above solution was transferred into the $10 \mathrm{~mL}$ volumetric flask and volume was made up to the mark with methanol. A volume $6 \mu \mathrm{L}$ of resulting solution was applied in triplicate on TLC plate followed by development and scanning as optimized chromatographic condition. The amount of Apremilast present in sample solution was determined by fitting peak area values of corresponding peak into the regression line equation representing calibration curve of Apremilast.

\section{Results and discussion}

\subsection{Analytical quality target profile (ATP) and critical quality attributes (CQAs)}

Development of stability indicating HPTLC method for estimation of apremilast which would be able to separate all spots of degradation products found in different stress conditions and apremilast with resolution of more than 1.5 with tailing factor of $0.9-1.2$ is set as analytical quality target profile (ATP). As per ATP, resolution and tailing factors of peaks found in chromatogram were selected as critical quality attributes for development of robust analytical method.

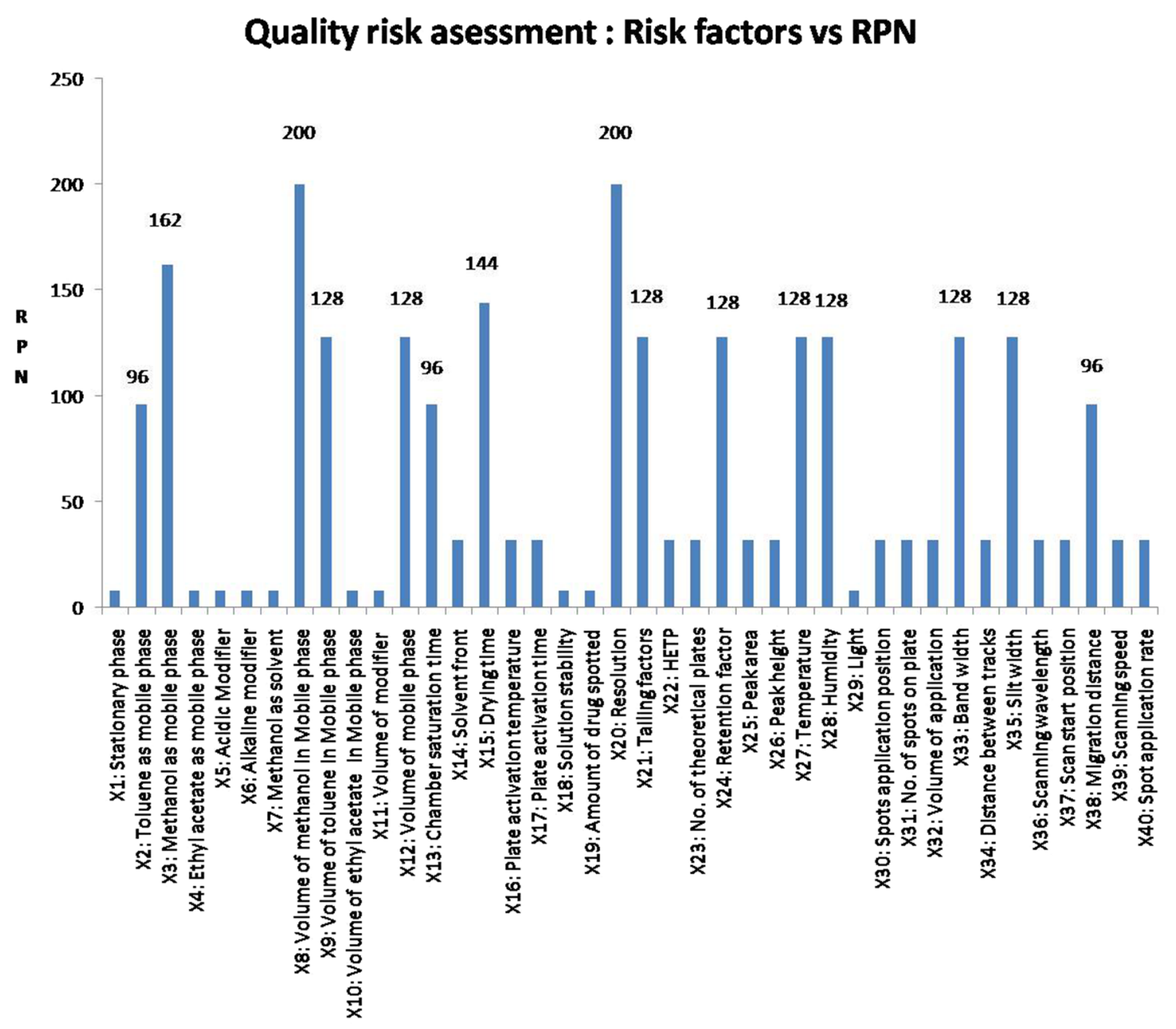

Risk Factors

Fig. 3 Graph of RPN score verses risk factors for quality risk assessment 
Design-Expert( Software

Resolution - 1

A: Volume of Methanol

B: Volume of Mobile Phase

C: Band Length

D: Saturation Time

E: Migration Distance

F: Detection Wavelength

G: Scanning speed

a Positive Effects

a Negative Effects

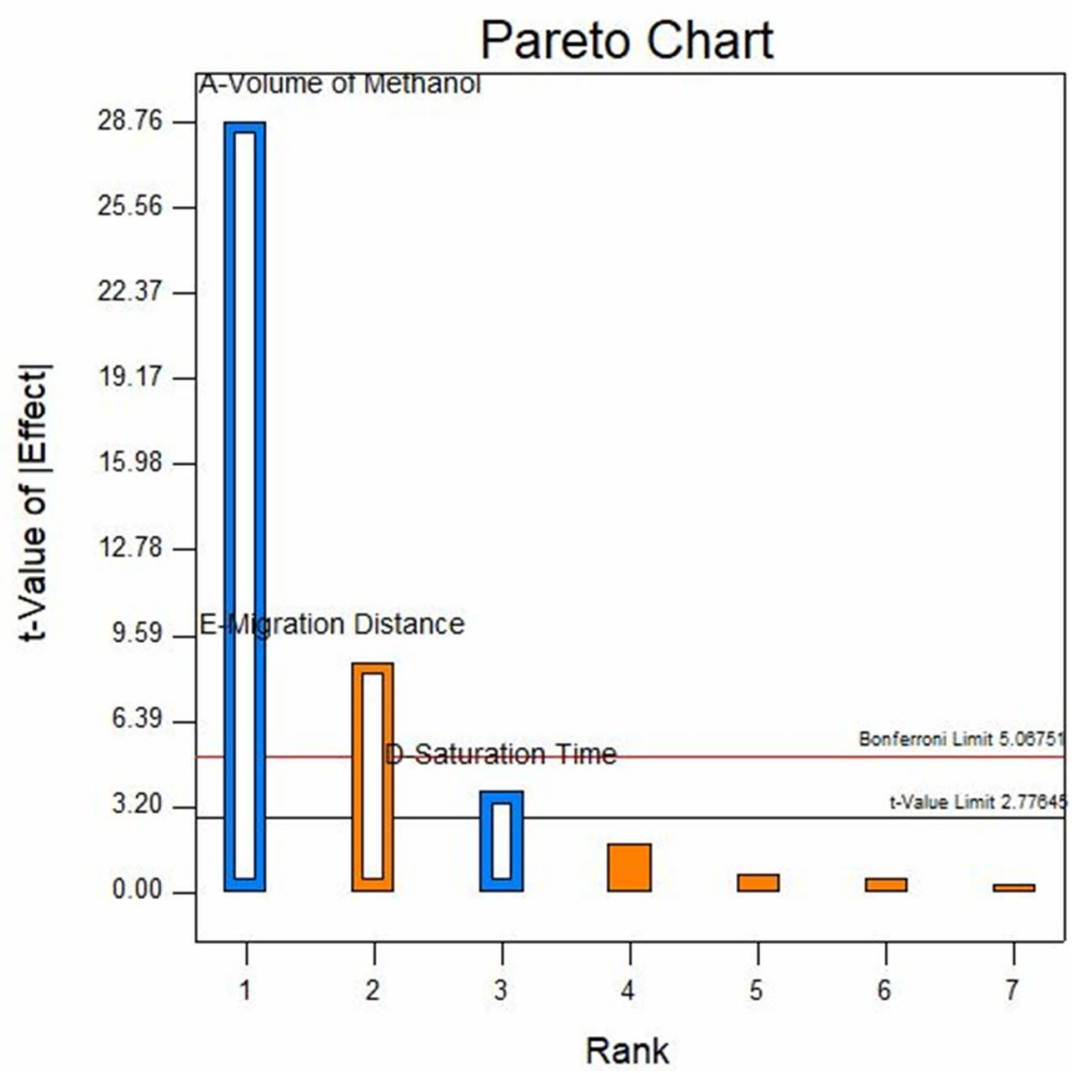

Fig. 4 Pareto chart for screening design of resolution-1

\subsection{Preliminary trials for Failure modes identification}

In present research work, the resolutions between peak of standard Apremilast and its degradation products were selected as critical method attribute for screening of potential method variable. From the results of preliminary trials, toluene, methanol and ethyl acetate were found as effective solvent for separation of spots of standard Apremilast and its degradation products. Apremilast is methanol soluble drug so volume of methanol would be more critical for stability indicating method. Other potential factors like saturation time, migration distance, volume of mobile phase, detection wavelength, scanning speed and band length were also found potential for resolution of spots. More than thirty identified failure modes were categorized in different class like material, method, machine, measurement, man and mother-nature (environment) and shown in Ishikawa diagram for better view of each failure mode for further analysis (see Fig. 2).

\subsection{Failure modes effect analysis (FMEA)}

Failure modes effect analysis was performed by allotting risk priority number to each failure mode listed in Ishikawa diagram by study of its occurrence, severity on quality of results and detectibility. Occurrence and severity of failure modes were measured by giving score to each failure mode based on its very low (02), low (04), medium (06), high (08) and very high (10) effect. Ability of detection of each failure modes very certain (02) to very uncertain (10) score has been allotted. RPN score has been calculated by multiplication of occurrence $(\mathrm{O})$, severity $(\mathrm{S})$ and detectibility (D) of each failure mode. Graph of RPN score verses failure modes were composed for failure mode effect analysis. Failure modes having RPN score above 60 were selected for further effect analysis for robust analytical method development. In method category, failure modes mobile phase composition, saturation time, volume of mobile phase was found RPN more than 60 . Under machine category, migration distance, slit dimension, wavelength for detection, band width were found high RPN. In mothernature category, temperature and humidity were found critical failure modes but they were not possible to consider and control. So air conditioning system was applied 
Design-Expert@ Software

Resolution - 2

A: Volume of Methanol

B: Volume of Mobile Phase

C: Band Length

D: Saturation Time

E: Migration Distance

F: Detection Wavelength

G: Scanning speed

a Positive Effects

- Negative Effects

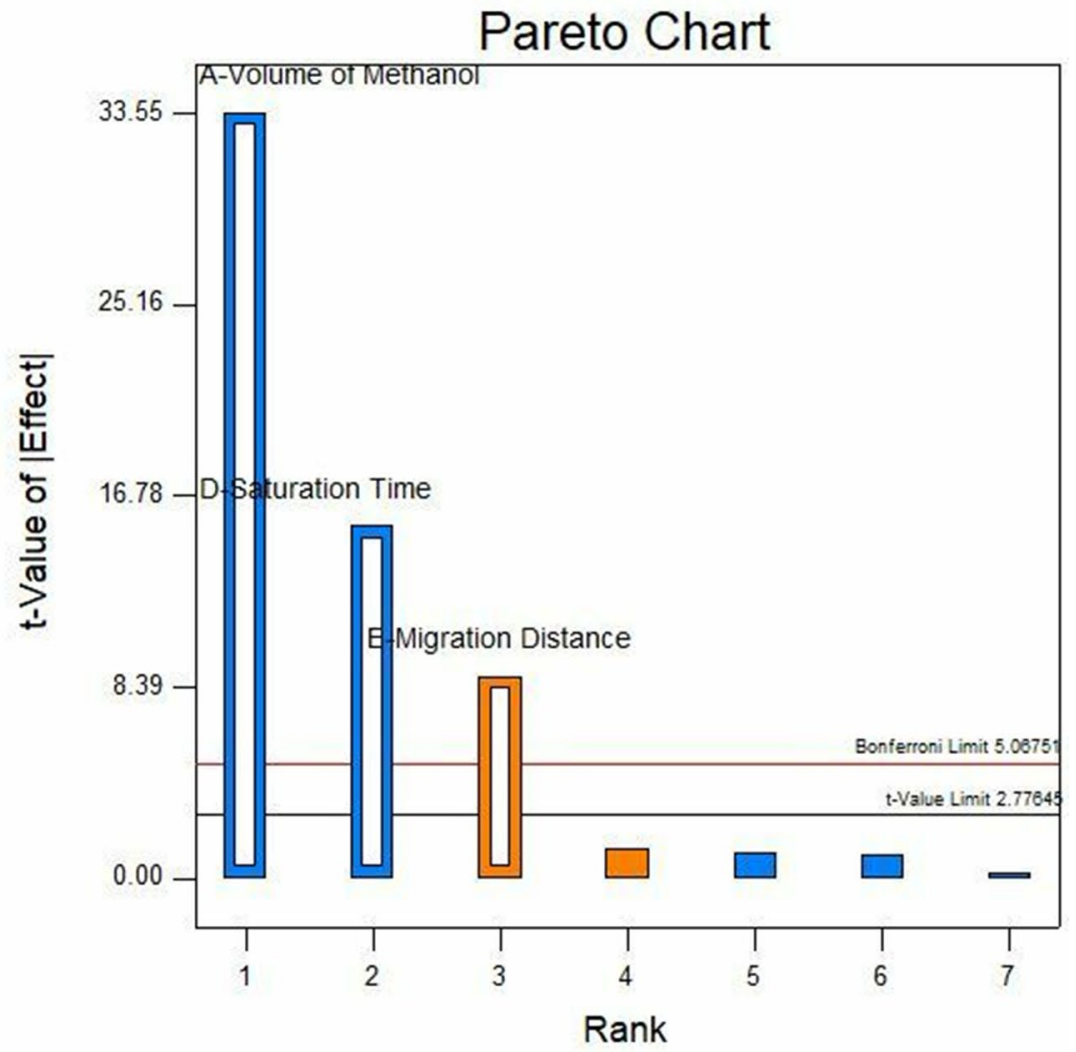

Fig. 5 Pareto chart for screening design of resolution-2

Table 9 ANNOVA table for Box-Behnken design

\begin{tabular}{|c|c|c|c|c|c|c|}
\hline Source & Sum of squares & $d f$ & Mean square & F value & $\begin{array}{l}p \text { value } \\
\text { Prob }>F\end{array}$ & \\
\hline Model & 2.51 & 5 & 0.50 & 145.19 & $<0.0001$ & Significant \\
\hline A-Volume of Methanol & 2.02 & 1 & 2.02 & 584.33 & $<0.0001$ & \\
\hline B-Migration distance & 0.065 & 1 & 0.065 & 18.90 & 0.0012 & \\
\hline C-Saturation time & 0.033 & 1 & 0.033 & 9.52 & 0.0104 & \\
\hline$A^{2}$ & 0.34 & 1 & 0.34 & 98.50 & $<0.0001$ & \\
\hline$C^{2}$ & 0.037 & 1 & 0.037 & 10.73 & 0.0074 & \\
\hline Residual & 0.038 & 11 & $3.457 \mathrm{E}-003$ & & & \\
\hline Lack of Fit & 0.028 & 7 & $4.069 \mathrm{E}-003$ & 1.70 & 0.3170 & Not significant \\
\hline Pure Error & $9.547 \mathrm{E}-003$ & 4 & $2.387 \mathrm{E}-003$ & & & \\
\hline Cor Total & 2.55 & 16 & & & & \\
\hline
\end{tabular}

to fix the effect of temperature and humidity on results of analytical method.

\subsection{Output of screening by Taguchi OA design}

Failure modes found to be critical were further analysed for their main effect on critical quality attributes by DoE based Taguchi OA design. So, finally volume of methanol (low level $=1.5 \mathrm{~mL}$ and high level $=2.5 \mathrm{~mL}$ ), saturation time (low level $=15 \mathrm{~min}$ and high level $=45 \mathrm{~min}$ ), migration distance (low level $=70 \mathrm{~mm}$ and high level $=80 \mathrm{~mm}$ ) volume of mobile phase (low level $=8.0 \mathrm{~mL}$ and high level $=10 \mathrm{~mL}$ ), scanning speed (low level $=10 \mathrm{~mm} / \mathrm{s}$ and high level $20 \mathrm{~mm} / \mathrm{s}$ ), detection wavelength (low level $=240 \mathrm{~nm}$ and high level $=242 \mathrm{~nm}$ ), band length (high level $=4 \mathrm{~mm}$ and low level $=6 \mathrm{~mm}$ ) were selected for development of HPTLC method for stability study of Apremilast. After entering the potential method variables with its level to Taguchi OA design the suggested runs by the software were performed in the laboratory and resolutions were entered in 


$$
\begin{aligned}
& \text { Design-Expert@ Software } \\
& \text { Resolution - } 4 \\
& \text { A: Volume of Methanol } \\
& \text { B: Volume of Mobile Phase } \\
& \text { C: Band Length } \\
& \text { D: Saturation Time } \\
& \text { E: Migration Distance } \\
& \text { F: Detection Wavelength } \\
& \text { G: Scanning speed } \\
& \text { a Positive Effects } \\
& \text { a Negative Effects }
\end{aligned}
$$

Fig. 6 Pareto chart for screening design of resolution-3

the design against respective experimental runs for data analysis (see Table 2). From ANNOVA table (see Tables 5, 6, $7,8)$, $F$ values for model was found to be $304.88,480.97$, 129.11 and 88.67 for resolutions 1, 2, 3 and 4 respectively which indicates that the models were significant and $p$-values were found less than 0.05 for volume of methanol, saturation time and migration distance for all four resolutions which indicates that this model terms were significant. $p$ values for scanning speed, detection wavelength, band width and volume of mobile phase were found greater than 0.05 which indicates that these model terms were giving insignificant effect on resolution between degradation products and standard peak of Apremilast. In Pareto charts (see Figs. 2, 3, 4, 5) bars of volume of methanol, saturation time, and migration distance were found above the line of significance while other bars were below the line of significance. From ANOVA and pareto chart analysis, volume of methanol, saturation time and migration distance were consider as critical method variables for optimization of chromatographic condition. From the screening design resolution between drug and acid degradation product-1 was found significant and was selected as a critical analytical attribute.

\subsection{Response surface modeling by Box-Behnken design}

Box-Behnken design was used for response surface analysis to determine relationship between critical method variables and attributes for development of robust HPTLC method. Seventeen numbers of experimental runs were suggested by design expert software (trial version) for Box-behnken design which were minimum as compare to other experimental designs of response surface modeling. All required experimental runs were performed in laboratory and measured resolutions were entered in software against respective experimental run for response surface analysis (see Table 6). ANOVA table showed model F-value of 52.91 implies the quadratic model is the best fit model (see Table 9). Values of probability less than 0.05 indicate model terms are significant. In this case, volume of methanol, migration distance and saturation time are significant main effects for response. All quadratic terms for volume of methanol and saturation time were found significant. From response surface model and contour plots (see Figs. $6,7,8$ ) analysis, the following mathematical model is used for optimization of responses. 
Design-Expert@ Software

Resolution - 3

A: Volume of Methanol

B: Volume of Mobile Phase

C: Band Length

D: Saturation Time

E: Migration Distance

F: Detection Wavelength

G: Scanning speed

a Positive Effects

- Negative Effects

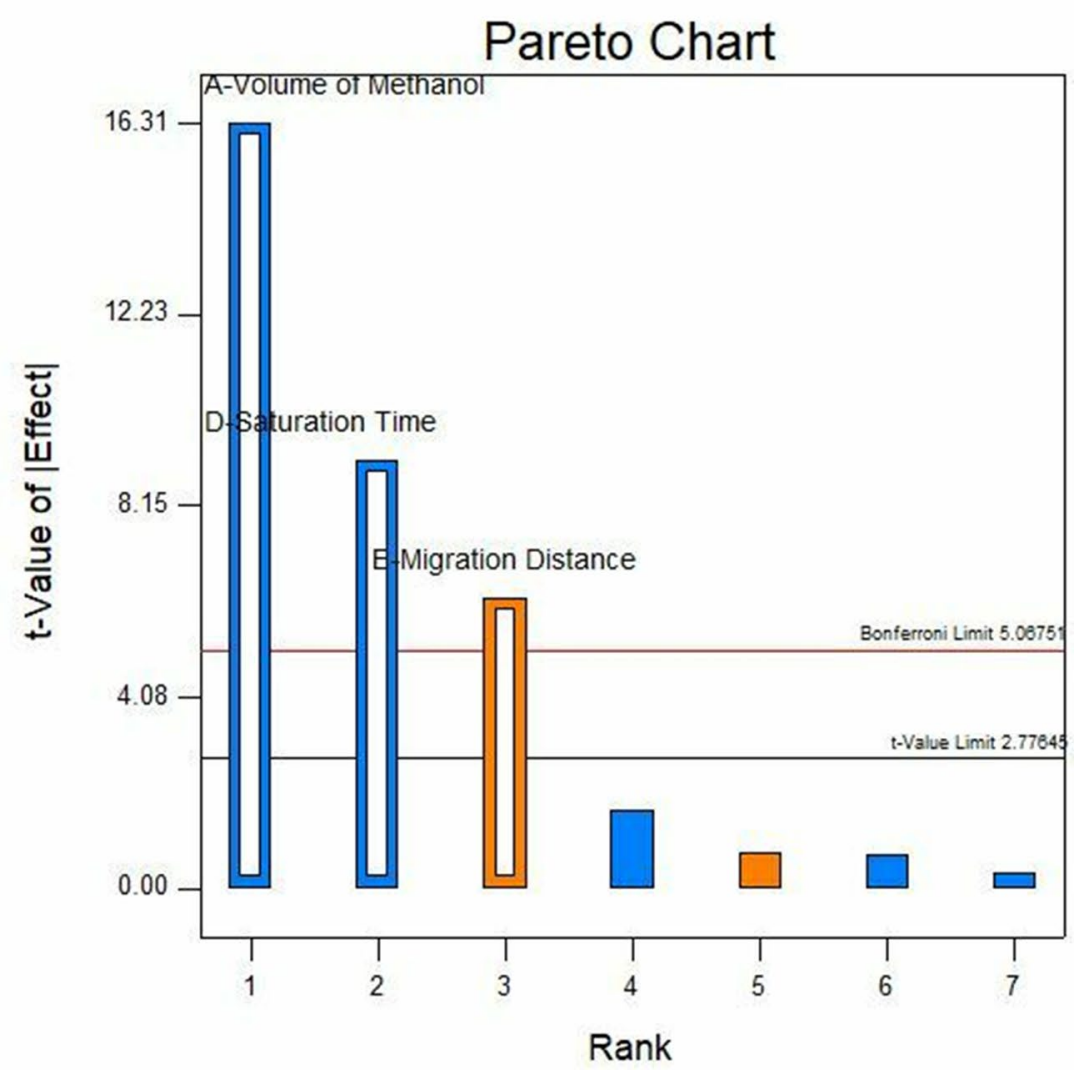

Fig. 7 Pareto chart for screening design of resolution-4

Resolution $=+1.60-0.50 *$ volume of methanol $+0.09 *$ migration distance

$-0.064 *$ saturation time $-8.50 * 10^{-3}$ volume of methanol $*$ migration distance

$+5.49 * 10^{-3}$ volume of methanol $*$ saturation time $+8.249 * 10^{-3}$ migration distance $*$ saturation time

$-0.284 *$ volume of methanol $^{2}+0.010 *$ migration distance $+0.094 *$ saturation time

After ignorance of insignificant terms the reduced mathematical model which was finally used for optimization of chromatographic condition for desired resolution is as follow to noise. The "Pred R-Squared" of 0.9599 is in reasonable agreement with the "Adj. R-Squared" of 0.9783 that implies predicted response would be in good agreement with experimental value of response (see Fig. 9).

Resolution $=-2.528+3.538 *$ volume of methanol $+0.018 *$ migration distance $+0.020 *$ saturation time

$-1.135 *$ volume of methanol $^{2}-4.166 * 10^{-4} *$ saturation time $^{2}$

The Lack of Fit F-value of 1.70 implies the Lack of Fit is not significant relative to the pure error. There is a $31.70 \%$ chance that a Lack of Fit F-value this large could occur due 

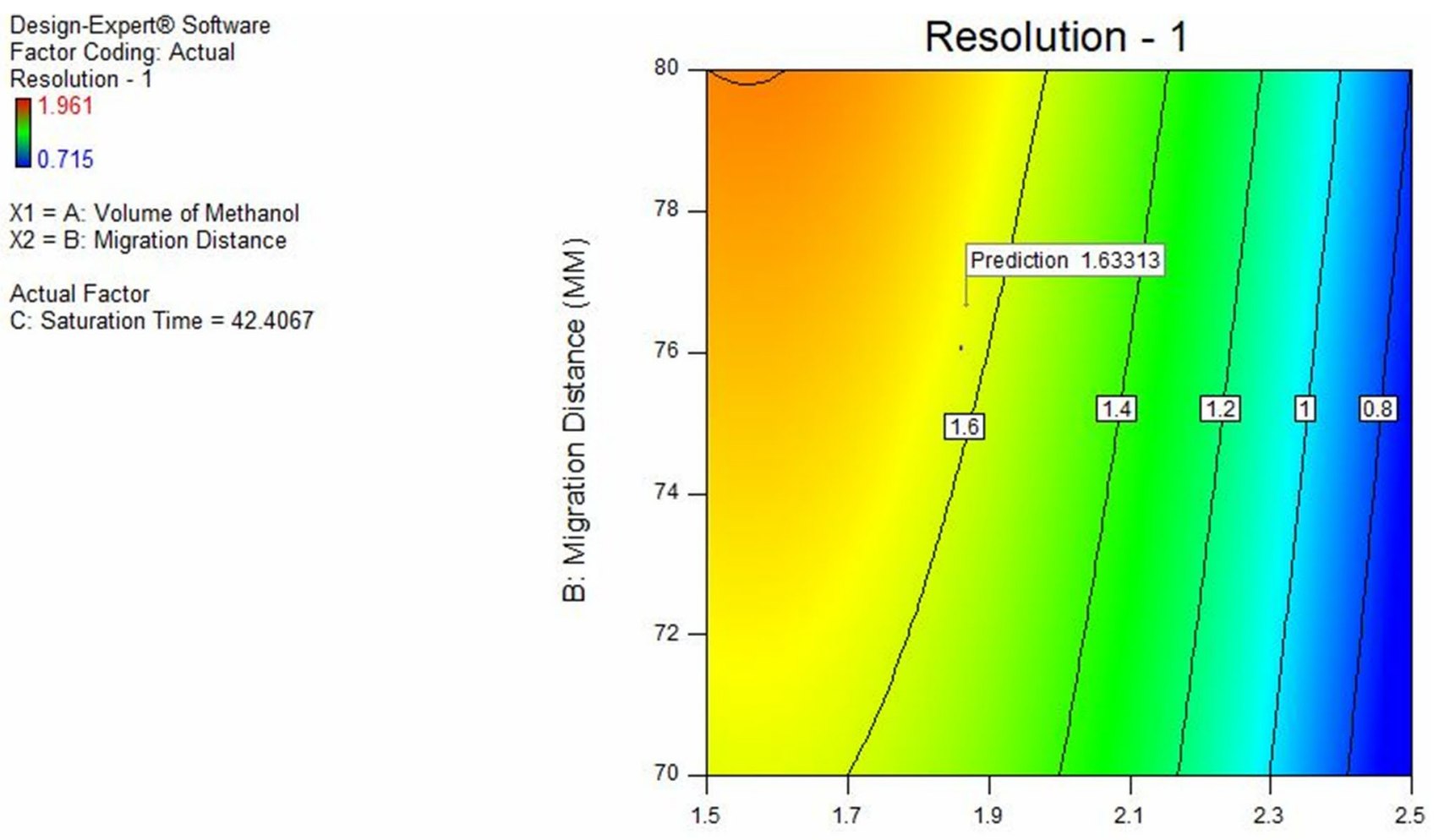

A: Volume of Methanol $(\mathrm{mL})$

Fig. 8 Contour plot of volume of methanol and migration distance

\subsection{Validation of the response surface model}

Small variations in the factors within the design space reflects that resolution is similar to that of predicted values (see Table 10), which shows better correlation between predicted and experimental values. Hence, it can be concluded that the suggested model is robust.

\subsection{Method operable design ranges (MODR) and control strategy}

After validating response surface model, design space (see Fig. 10) was defined for optimized chromatographic development to get desirable resolution between peaks of standard Apremilast and degradation product. According to design space the following control strategy was implemented for development of analytical method with resolution of more than 1.5 .

\begin{tabular}{lll}
\hline Method variables & Operating range & Selected condition \\
\hline Volume of methanol & $1.5-2.5 \mathrm{~mL}$ & $2 \mathrm{~mL}$ \\
Migration distance & $70-80 \mathrm{~mm}$ & $80 \mathrm{~mm}$ \\
Saturation time & $15-45 \mathrm{~min}$ & $30 \mathrm{~min}$ \\
\hline
\end{tabular}

\begin{tabular}{lll}
\hline Method variables & Operating range & Selected condition \\
\hline Band length & $4-6 \mathrm{~mm}$ & $6 \mathrm{~mm}$ \\
Detection wavelength & $240-242 \mathrm{~nm}$ & $241 \mathrm{~nm}$ \\
Scanning speed & $10-20 \mathrm{~mm} / \mathrm{s}$ & $20 \mathrm{~mm} / \mathrm{s}$ \\
Volume of mobile phase & $8-10 \mathrm{~mL}$ & $10 \mathrm{~mL}$ \\
\hline
\end{tabular}

\subsection{Selection of detection wavelength}

The spots of standard Apremilast were scanned in the range of 200-800 nm using Camag TLC scanner IV. The in situ UV spectrum of standard Apremilast showed maximum absorbance at $241 \mathrm{~nm}$. Hence, $241 \mathrm{~nm}$ was selected as the wavelength for measurement for estimation of Apremilast. 
Design-Expert@ Software

Factor Coding: Actual

Resolution - 1

T1.961

0.715

$\mathrm{X} 1=\mathrm{A}:$ Volume of Methanol

X2 = C: Saturation Time

Actual Factor

B: Migration Distance $=76.6618$

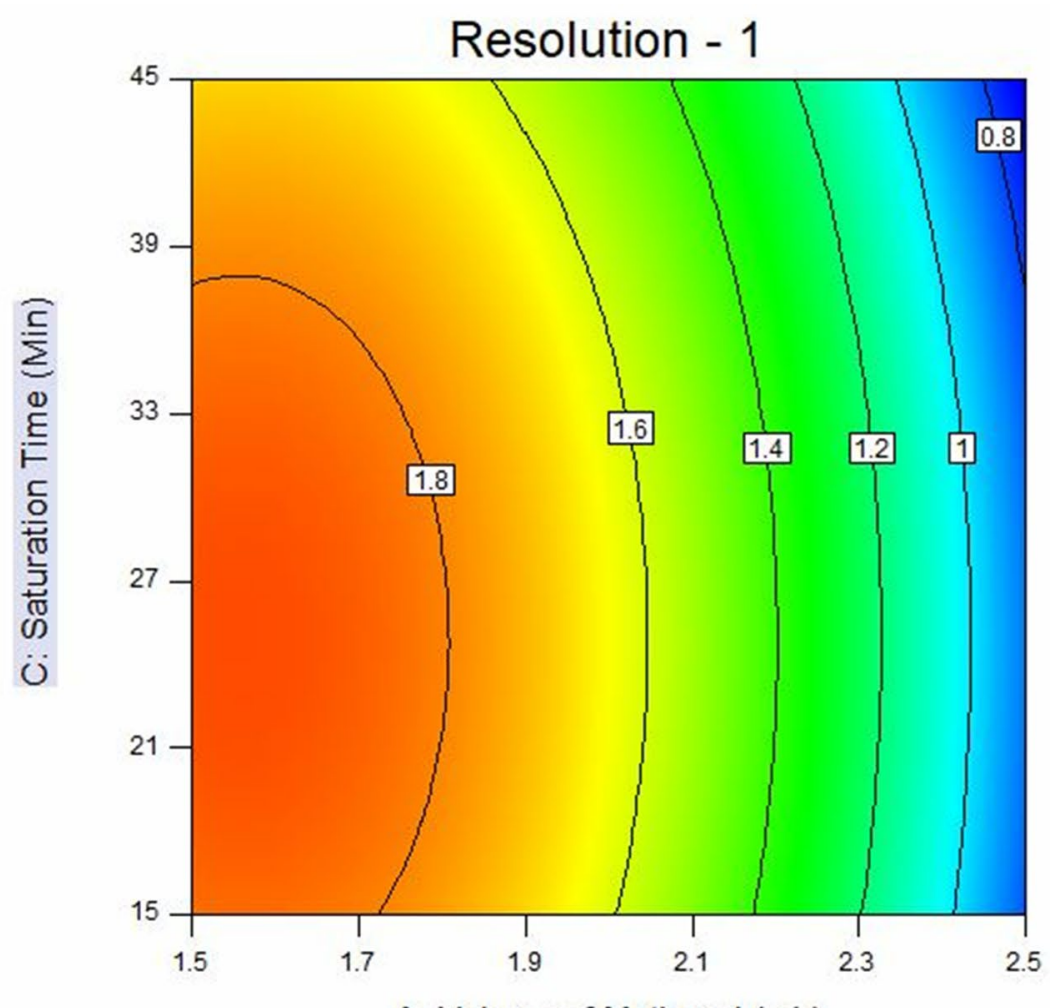

A: Volume of Methanol $(\mathrm{mL})$

Fig. 9 Contour plot of volume of methanol and saturation time

Table 10 Actual versus predicted values for resolution

\begin{tabular}{llll}
\hline $\begin{array}{l}\text { Predicted } \\
\text { resolution }\end{array}$ & Actual resolution & Difference & Correlation coefficient \\
\hline 1.789 & 1.736 & 0.053 & 0.941 \\
1.506 & 1.565 & 0.059 & \\
1.748 & 1.712 & 0.036 & \\
1.634 & 1.603 & 0.031 & \\
1.672 & 1.666 & 0.006 & \\
\hline
\end{tabular}

\subsection{Analysis of force degraded sample}

Apremilast was subjected to acidic, alkaline, oxidative, dry heat, neutral and photolytic degradation condition. The chromatogram of acid treated Apremilast showed two additional peaks at $R_{\mathrm{f}} 0.58$ and 0.15 (Fig. $11 \mathrm{~b}$ ), the chromatogram of alkali treated Apremilast showed one additional peak at $R_{f} 0.14$ (Fig. 11c), the chromatogram of hydrogen peroxide treated Apremilast showed no additional peaks (Fig. 11d), the chromatogram of distilled water treated Apremilast showed one additional peak at $R_{f} 0.18$ (Fig. 11e), the chromatograms of Apremilast treated under photolytic degradation condition showed no additional peak (Fig. 11f) and the chromatogram of dry heat treated Apremilast showed no additional peak (Fig. 11g) as compared to chromatogram of standard Apremilast (Fig. 11a). From degradation study data it is observed that Apremilast is more prone to alkaline hydrolysis but less prone to acid and neutral hydrolysis and was found stable in oxidative, dry heat and photolytic stress conditions. The data of percentage degradation of Apremilast in all stress conditions is shown in Table 11. The different stress conditions 


\section{Design-Expert@ Software \\ Factor Coding: Actual \\ Resolution - 1

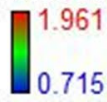

$\mathrm{X} 1=\mathrm{B}:$ Migration Distance

X2 = C: Saturation Time

Actual Factor

A: Volume of Methanol $=1.86901$

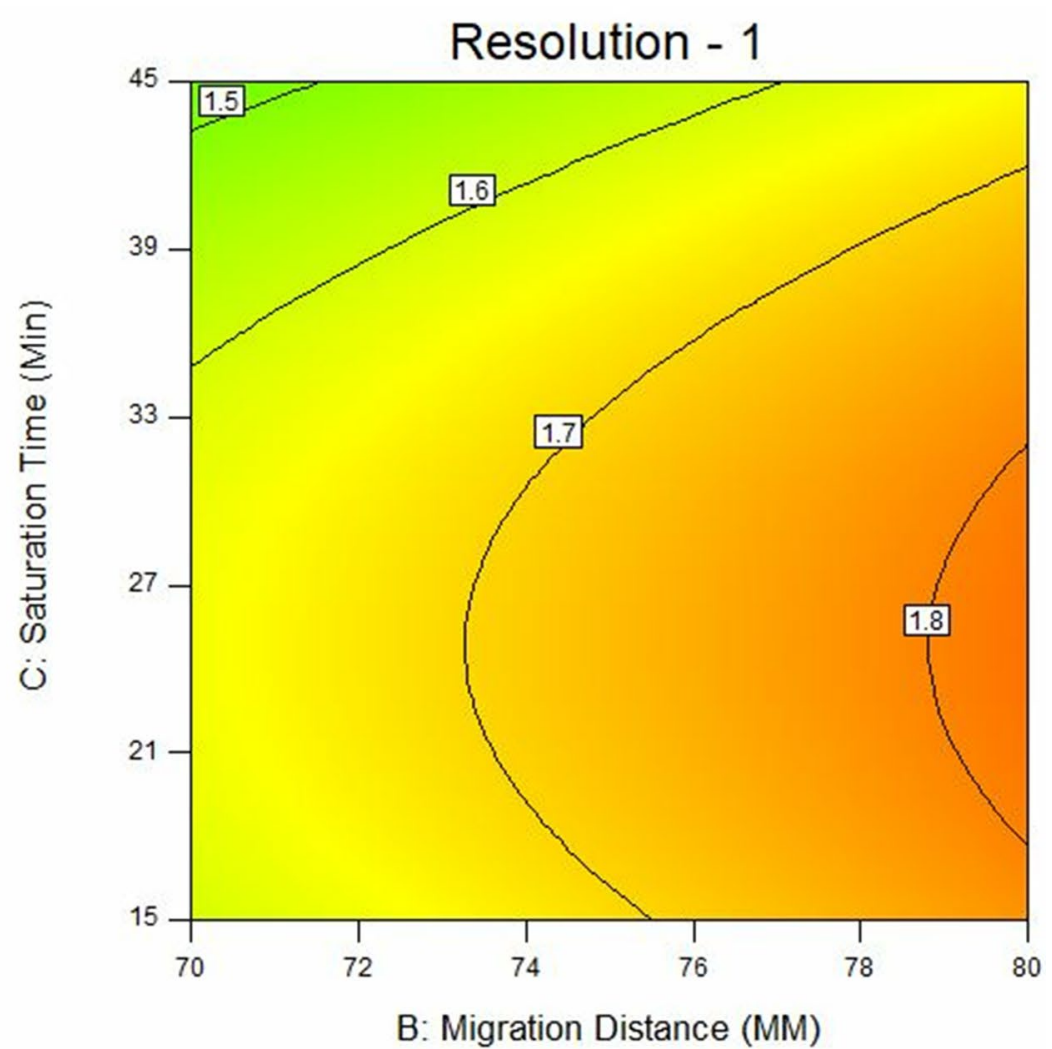

Fig. 10 Contour plot of migration distance and saturation time

were applied for forced degradation study of apremilast to achieve $20-30 \%$ degradation for development of stability indicating HPTLC method as per ICH Q1R2 guideline (Figs. 12, 13).

\subsection{Method validation}

Comparison of chromatograms of standard Apremilast and tablet formulation of both Apremilast showed identical $R_{f}$ values of $0.63 \pm 0.02(n=3)$. Excipients and other components present in formulation did not interfere in $R_{f}$ of drug. Comparison of the UV absorbance spectra scanned at peak start (s), peak apex ( $\mathrm{m}$ ) and peak end (e) positions of individual spots Apremilast showed a high degree of correlation, confirmed the purity of the corresponding spots. The purity of standard and sample Apremilast were almost identical. Developed method was found to be linear in the range of 200-1000 ng/band with correlation coefficient of 0.996. The \% RSD for repeatability of sample measurement and sample application was found to be 0.44 and 0.94 respectively. $\%$ RSD for inter-day and intra-day precision was found to be in the range of 0.43-1.07 and 0.11-0.42 respectively. \% recovery data for accuracy was found to be in the range of 98.70 to $99.66 \%$ which indicates the method is accurate. Summary of validation parameter is depicted in Table 12.

\subsection{Assay of marketed formulation}

The assay of marketed formulation (tablet) was found to be $102 \%$ (see Table 13). The chromatogram shows peak of Apremilast at $R_{f}$ of 0.062 with no additional peak which indicate no interference of excipients in estimation of Apremilast.

\section{Discussion of results}

Objective of the present study was to develop a validated stability indicating HPTLC method that is capable of accurately estimate Apremilast. The quality by design approach is a recent trend in development of analytical methods where a science based risk assessment is carried out. Hence analytical quality by design approach was used to develop the present stability indicating analytical method.

The drug was found to be degraded in acidic, alkaline and neutral stress conditions while it was found stable in photolytic, dry heat and oxidative stress conditions. For development of stability indicating analytical method 


\section{Design-Expert@ Software}

Resolution - 1

Color points by value of Resolution - 1 :

1.961

0.715

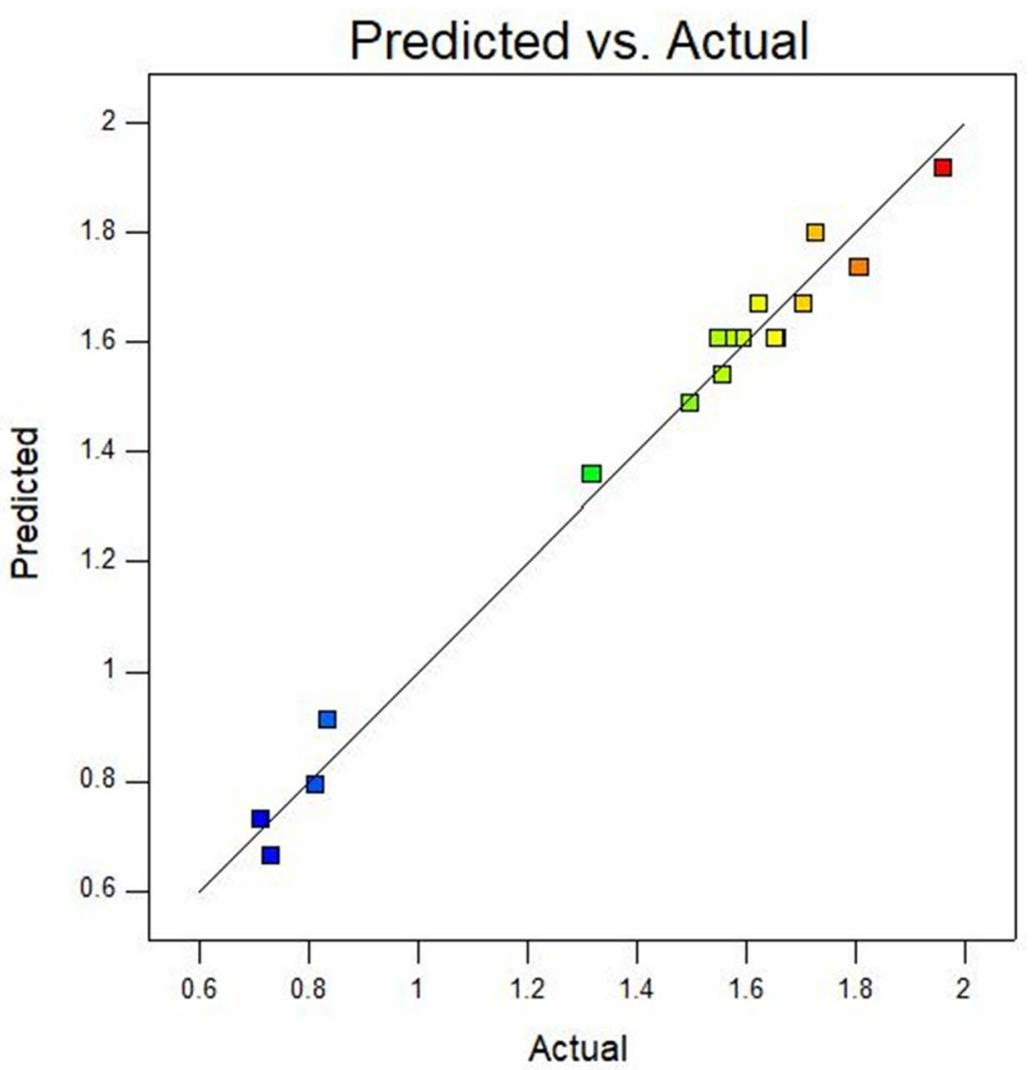

Fig. 11 Actual versus predicted resolution

Table 11 Summary of force degradation study of Apremilast

\begin{tabular}{llll}
\hline Sr.no. & Stress type & Stress conditions & \% Degradation \\
\hline 1 & Acidic degradation & $0.1 \mathrm{M} \mathrm{HCl}$ at $60^{\circ} \mathrm{C}$ for $1 \mathrm{~h}$ & $23.90 \%$ \\
2 & Alkaline degradation & $0.01 \mathrm{M} \mathrm{NaOH}$ at Room temperature for & $10.45 \%$ \\
& & $15 \mathrm{~min}$ & \\
3 & Oxidative degradation & $6 \% \mathrm{H}_{2} \mathrm{O}_{2}$ at $80^{\circ} \mathrm{C}$ for $4 \mathrm{~h}$ & Drug was stable \\
4 & Photolytic degradation & Direct exposed to Sunlight for $8 \mathrm{~h}$ & Drug was stable \\
5 & Dry Heat degradation & Dry heat $110{ }^{\circ} \mathrm{C}$ for $4 \mathrm{~h}$ & Drug was stable \\
6 & Hydrolytic degradation & At $50^{\circ} \mathrm{C}$ for $1 \mathrm{~h}$ & $9.56 \%$ \\
\hline
\end{tabular}

resolution between drug and degradation product is crucial hence resolutions between drug and degradation products were selected as potential method attributes and seven factors like volume of methanol, volume of mobile phase, migration distance, scanning speed, detection wavelength, saturation time and band length were selected as potential method variables. By applying Taguchi OA screening design 3 potential method variable volume of methanol, migration distance and saturation time and one critical method attribute that is resolution between drug and acid degradation product- 1 which is adjacent to the drug peak were screened from the four potential method attributes. Further the screened critical method variables were taken to Box-behnken design to establish the relationship between critical method variables and critical quality attribute and design space was generated using the suggested quadratic model. The developed method was found to be accurate, linear, precise and specific. Results for the estimation of Apremilast in marketed formulation (Aprezo Tablets, Glenmark Life Sciences) indicate that proposed method could be effectively used for estimation of Apremilast in tablet dosage form. 
Design-Expert( Software

Factor Coding: Actual

Overlay Plot

Resolution - 1

- Design Points

$\mathrm{X} 1=\mathrm{B}:$ Migration Distance

X2 = C: Saturation Time

Actual Factor

A: Volume of Methanol $=2$

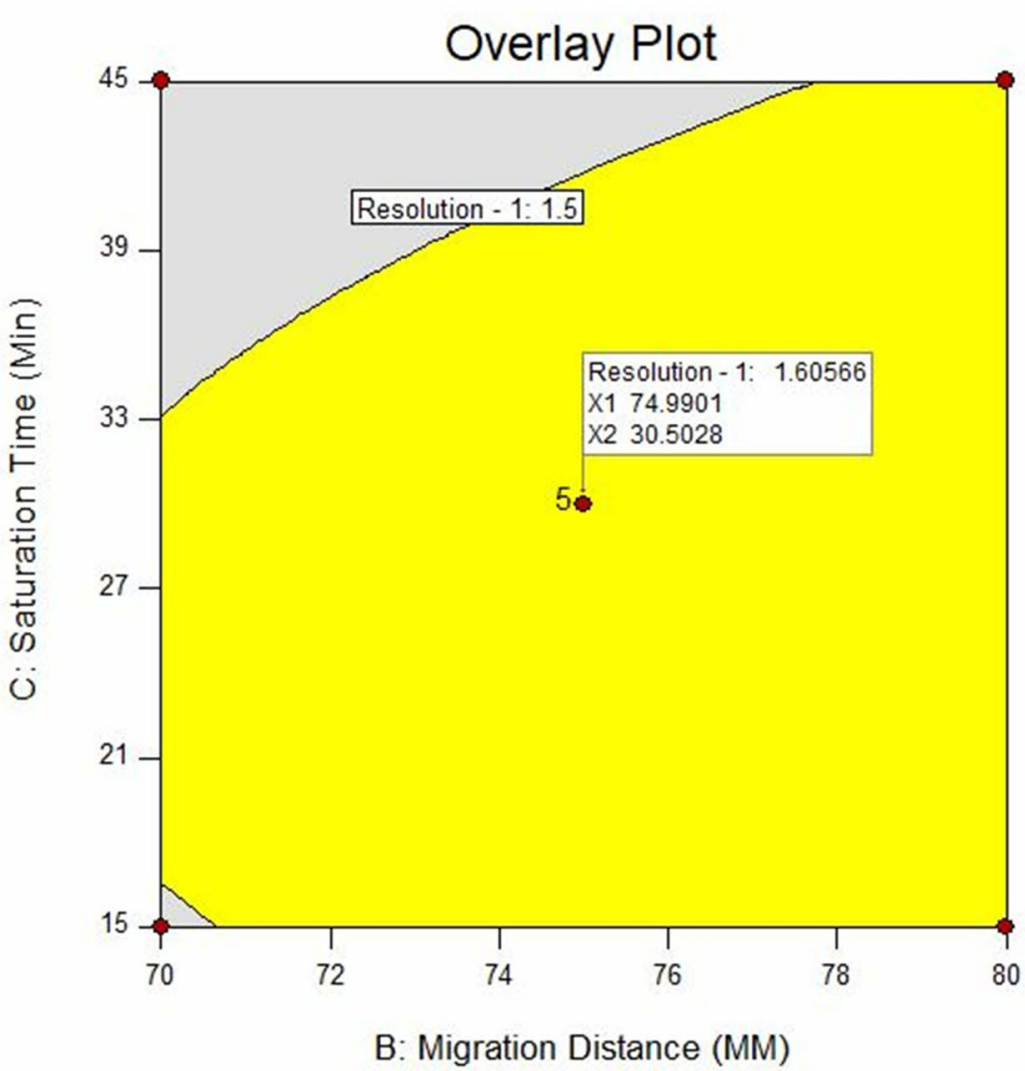

Fig. 12 Design space for resolution more than one as per QTAP

\section{Conclusion}

Implementation of analytical quality by design approach for development of stability indicating HPTLC method was performed by quality risk management tool failure mode effect analysis. As compare to reported analytical method in literature, the present method is exemplary research work how to implement analytical quality by design approach based on quality risk management to analytical method development as per regulatory requirement of ICH Q8 and Q9 for registration of new drug substances and products. Analytical quality by design implementation is always incomplete without quality risk management for development of robust analytical method and its life cycle management. An efficient AQbD approach was utilized to develop a competent stability indicating HPTLC method for estimation of Apremilast in its pharmaceutical dosage form. The approach gives better consideration of the factors influencing chromatographic separation and greater assurance in the ability of the methods to meet their intended purpose. Seven potential method variables were employed to Taguchi OA screening design for identification of critical method variable using resolution between drug and acid degradation product as a response where three factors namely volume of methanol, migration distance and saturation time were identified as critical method parameters which was further used for optimization using Box-Behnken response surface design with the least number of possible runs at three different levels. The experimental design describes the HPTLC method components including saturation, migration distance, and mobile phase composition. Their interrelationships are studied and optimized conditions are obtained. Short migration distance, fast speed, satisfactory accuracy, and precision are the main features of this analytical method. The method was successfully validated as per ICH guidelines. The method was found specific, as there was no any interfering peak with that of standard peak of Apremilast. The approach has been successfully used to develop 

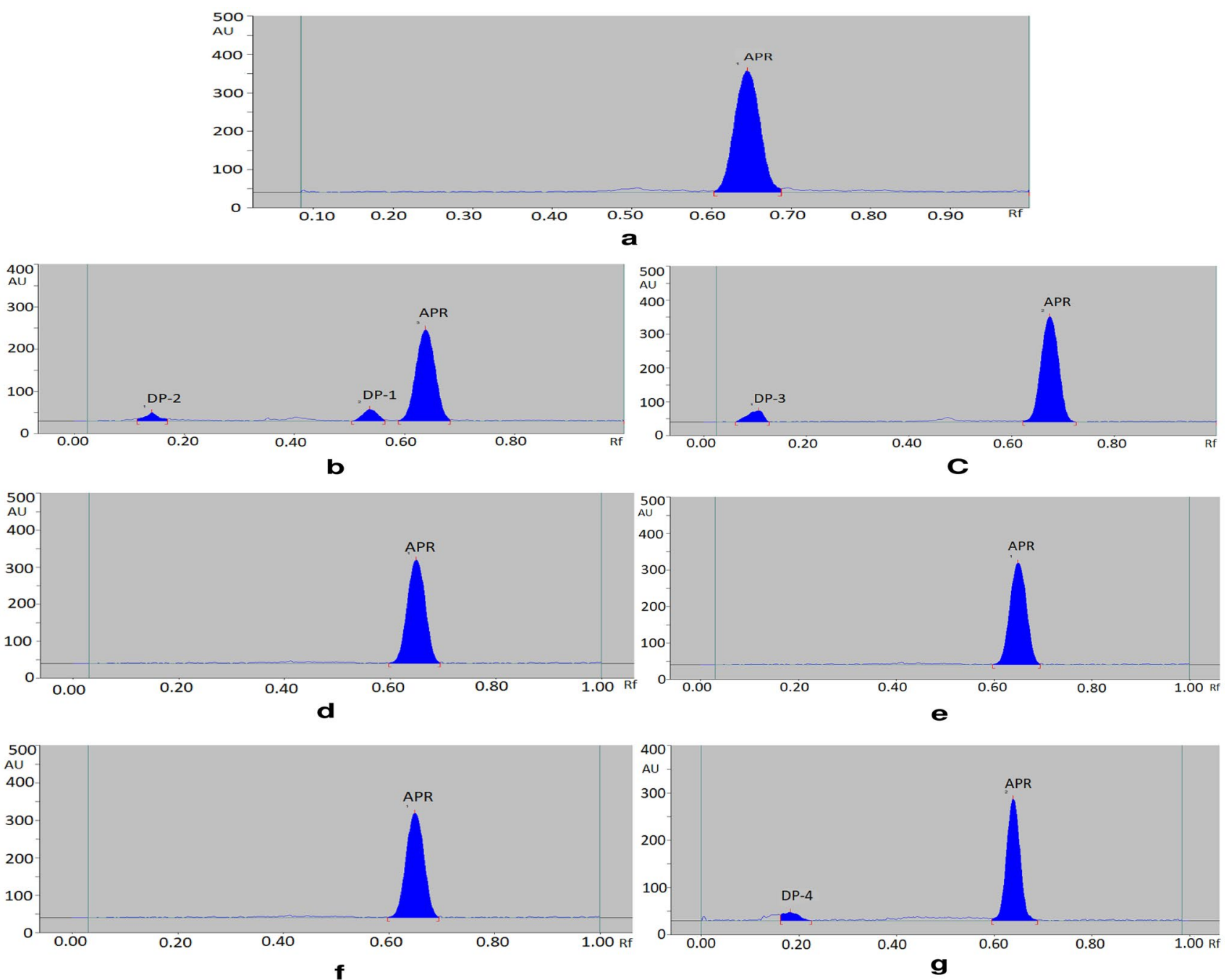

Fig. 13 a Standard Densitogram of Apremilast, b Densitogram of Apremilast in Acidic condition, $\mathbf{c}$ Densitogram of Apremilast in Alkaline condition, $\mathbf{d}$ Densitogram of Apremilst in Oxidative condi-

tions, $\mathbf{e}$ Densitogram of Apremilast in Dry heat condition, $\mathbf{f}$ Densitogram of Apremilast in Photolytic condition, $\mathbf{g}$ Densitogram of Apremilast in Neutral condition 
Table 12 Summary of method validation of Apremilast

\begin{tabular}{lll}
\hline Sr. no. & Parameters & Results \\
\hline 1 & Linearity range & $200-1000 \mathrm{ng} / \mathrm{band}$ \\
2 & Regression equation & $\mathrm{y}=6.8696 \mathrm{x}-933.66$ \\
3 & Regression coefficient $\left(\mathrm{R}^{2}\right)$ & 0.996 \\
4 & Precision (RSD) & \\
& Repeatability of sample application $(\mathrm{n}=7)$ & $0.90 \%$ \\
& Repeatability of sample measurement $(\mathrm{n}=7)$ & $0.11 \%$ \\
& Intermediate precision & \\
& Inter-day precision $(\mathrm{n}=3)$ & $0.43-0.74 \%$ \\
& Intra-day precision $(\mathrm{n}=3)$ & $0.11-0.42 \%$ \\
7 & Limit of detection (LOD) & $4.42 \mathrm{ng}$ \\
& Limit of quantification (LOQ) & $13.40 \mathrm{ng}$ \\
\hline
\end{tabular}

Table 13 Analysis of marketed formulation

\begin{tabular}{llll}
\hline $\begin{array}{l}\text { Marketed formula- } \\
\text { tion }\end{array}$ & Labelled claim & $\begin{array}{l}\text { Amount of drug } \\
\text { found }\end{array}$ & $\%$ Assay \\
\hline Tablet & $30 \mathrm{mg}$ & $30.6 \mathrm{mg}$ & $102 \%$ \\
\hline
\end{tabular}

HPTLC method for estimation of Apremilast in marketed pharmaceutical tablet dosage form.

Acknowledgements The authors are thankful to Sun Pharmaceuticals, Vadodara for providing the gift sample of Apremilast and Principal of Maliba Pharmacy College for providing the resources for the work.

\section{Compliance with ethical standards}

Conflict of interest The authors declare that they have no conflict of interest

\section{References}

1. Snehalatha K, Ravindranathan R, Sriram DK, George M (2018) Utility of apremilast in the treatment of psoriasis. Int J Basic Clin Pharmacol 7(8):1450-1453

2. Cauli A, Porru G, Piga M, Vacca A, Dessole G, Mathieu A (2014) Clinical potential of apremilast in the treatment of psoriatic arthritis. ImmunoTargets Therapy 3:91-96

3. Attimarad M, Mueen Ahmed KK, Aldhubaib BE, Harsha S (2011) High-performance thin layer chromatography: a powerful analytical technique in pharmaceutical drug discovery. Pharmaceut Methods 2(2):71-75

4. Sangshetti JN, Deshpande M, Zaheer Z, Shinde D, Arote R (2017) Quality by design approach: regulatory need. Arab J Chem 10(2):S3412-S3425

5. Dejaegher B, Heyden YV (2011) Experimental designs and their recent advances in set-up, data interpretation, and analytical applications. J Pharmaceut Biomed Anal 56(2):141-158

6. Bhutani H, Kurmi M, Beg S, Singh B (2014) Quality by design $(\mathrm{QbD})$ in analytical sciences: an overview. Pharma Times 46:71-75

\section{SN Applied Sciences}

7. Vogt FG, Kord AS (2011) Development of quality-by-design analytical methods. J Pharmaceut Sci 100(3):797-812

8. Ravisankar P, Sulthana MD, Babu PS (2017) Development and validation of stability-indicating UV spectrophotometric method for determination of Apremilast in bulk and pharmaceutical dosage form. Indian J Res Pharmacy Biotechnol 5:47-53

9. Lonkar NA, Dole MN, Sawant SD (2017) Development and validation of uv-spectrophotometric method for the estimation of apremilast in bulk form by absorbance maxima method. World J Pharmacy Pharmaceut Sci 6:758-766

10. Kulsum S, Sagar GV, Butul A, Fatima S, Sami Uddin MD (2016) Method development and validation of forced degradation studies of apremilast by using uv spectrophotometric method. World J Pharmacy Pharmaceut Sci 5:1595-1601

11. Panchumarthy R, Sulthana S, Kamma H (2017) Development and validation of a stability-indicating reversed phase HPLC method for determination of apremilast in bulk and pharmaceutical dosage form. Der Pharmacia Lettre 9:63-73

12. Anerao A, Telange V, Bondre N, John S, Gadhave T, Pradhan N (2017) Stability-indicating related substances method of apremilast by HPLC and synthesis and chracterization of related impurities using mass and NMR spectroscopy. Int J Curr Med Pharmaceut Res 3:1378-1385

13. Landge SB, Dahale SB, Jadhav SA, Solanki PV, Bembalkar SR, Mathad VT (2017) Development and validation of stability indicating rapid RP-LC method for determination of process and degradation related impurities of apremilast, an anti-inflammatory drug. Am J Anal Chem 8(6):380-394

14. Chaudhari SR, Shirkhedkar AA (2018) Application of BoxBehnken design for validation of high-performance thin-layer chromatography/densitometry method for robustness determination of apremilast in bulk and in house tablets. Pharmaceut Methods 9(1):8-14

15. Bhole Ritesh P et al (2019) A stability indicating HPTLC method for apremilast and identification of degradation products using MS/MS. J Pharmaceut Sci Res 11(5):1861-1869

16. ICH, Q2 (R1) (2005) Harmonized tripartite guideline, validation of analytical procedures: text and methodology. In: Proceedings of the international conference on harmonization of technical requirements for registration of pharmaceuticals for human use

Publisher's Note Springer Nature remains neutral with regard to jurisdictional claims in published maps and institutional affiliations. 